\title{
REFLEXÕES SOBRE O PROGRAMA NACIONAL DE ALIMENTAÇÃO ESCOLAR - PNAE
}

\author{
Graziella Plaça Orosco de Souza ${ }^{1}$
}

\section{Aparecida José Martines de Oliveira ${ }^{2}$}

\section{Edilene Mayumi Murashita Takenaka ${ }^{3}$}

\begin{abstract}
RESUMO
No intuito de desmistificar a visão assistencialista projetada pela sociedade civil e sua participação na operacionalização das políticas públicas, o trabalho discute sobre o Programa Nacional de Alimentação Escolar - PNAE, apontando potencialidades e fragilidades na região do Pontal do Paranapanema. Foram observados estudos de casos, legislações, e analisado o Programa para se comparar sua proposta e o que os estudos apontaram neste sentido. Constatou-se que a maior participação da sociedade poderia contribuir para a desmistificação do objeto norteador do programa, que se distancia do assistencialismo.
\end{abstract}

PALAVRAS-CHAVE: Programa Nacional de Alimentação Escolar - PNAE. Políticas Públicas. Agricultor Familiar.

\section{Reflections on the National School Feeding Programme - PNAE}

\author{
ABSTRACT \\ In order to demystify the welfarism vision projected by the civil society and its participation in the \\ operationalization of public policies, this paper discusses about the National School Feeding Program - \\ PNAE, pointing out strengths and weaknesses in the Pontal do Paranapanema region. Studies of cases

\footnotetext{
${ }^{1}$ Mestranda do Curso de Mestrado em Meio Ambiente e Desenvolvimento Regional - MMADRE. Universidade do Oeste Paulista - UNOESTE. E-mail: graza@unoeste.br.

Mestre em Educação. Universidade do Oeste Paulista - UNOESTE. E-mail: cidinhamartines@unoeste.br.

${ }^{3}$ Docente do Curso de Mestrado em Meio Ambiente e Desenvolvimento Regional - MMADRE. Universidade do Oeste Paulista - UNOESTE. E-mail: edilene@unoeste.br.
} 
and laws were observed, and the Program was analyzed in order to compare their proposal and what the studies point to this direction. It was found that the greater participation of society could contribute to the demystification of the guiding object of program, which moves away from welfarism.

KEY-WORDS: National School Feeding Program - PNAE. Public Policies. Family Farmer.

\section{Programa de Alimentación Escolar Nacional - PNAE}

\section{RESUMEN}

Con el fin de desmitificar la visión asistencialista proyectada por la sociedad civil y su participación en la operación de las políticas públicas, el trabajo discute sobre el Programa de Alimentación Escolar Nacional - PNAE, destacando los puntos fuertes y débeles en la región del Pontal del Paranapanema. No se observaron casos de estudio, las leyes, y analizaron el Programa para comparar su propuesta y lo que los estudios apuntan en esta dirección. Se encontró que la más intensa participación de la sociedad puede contribuir a la desmitificación de guiar el objeto del programa que se aleja de bienestar.

PALABRAS CLAVE: Programa de Alimentación Escolar Nacional - PNAE. Políticas Públicas. Agricultor Familiar.

\section{INTRODUÇÃO}

As políticas públicas no Brasil, desde sua concepção, carregam a marca do assistencialismo. Até a década de 1980, o Estado tomava para si a responsabilidade de elaborar, gerenciar e executar políticas públicas que propiciem saúde, educação, e demais serviços com qualidade para os cidadãos. A partir da década de 1990, no governo de Fernando Henrique Cardoso, a Reforma do Estado promovida pelo exministro Bresser Pereira previu que as políticas públicas nas áreas de Cultura, Educação, Lazer, Esporte, Ciência e Tecnologia seriam apenas gerenciadas pelo Estado.

No intuito de conceituar a questão, torna-se importante salientar o significado de Estado e de políticas públicas. Estado pode ser considerado como o conjunto de órgãos autônomos harmônicos e independentes entre si, que determinam conforme ordenamento jurídico nacional a operacionalização de políticas e programas governamentais que são explicitadas cada qual em sua esfera de poder. Política pública, por sua vez, pode ser conceituada como mecanismo e/ou instrumento que o Estado tem para promover o bem comum. Secchi (2010), ao construir o conceito do 
termo, define que "uma política pública é uma diretriz elaborada para enfrentar um problema público" (SECCHI, 2010, p. 1).

Ainda de acordo com Secchi (2010), dois são os sentidos da palavra política, sendo o primeiro referente à ação humana atrelada a concepção de atividade e competição política. O segundo sentido da palavra tem relação com "orientações para a decisão e ação". Assim, de acordo com Secchi (2010),

O termo política pública (public policy) está vinculado a esse segundo sentido da palavra política. Políticas públicas tratam do conteúdo concreto e do conteúdo simbólico de decisões políticas, e do processo de construção e atuação dessas decisões (SECCHI, 2010, p.1. Grifos do autor).

Para simplificar o conceito, segundo Höfling (2001, p. 31):

Políticas públicas são aqui entendidas como o "Estado em ação" (apud Gobert, Muller, 1987); é o Estado implantando um projeto de governo, através de programas, de ações voltadas para setores específicos da sociedade (HÖFLING, 2001, p. 31).

Assim, a Reforma de Estado acaba por promover maior participação da sociedade civil, que passam a atuar junto ao Estado na concepção e gerenciamento das políticas públicas. Neste momento da história política brasileira, as Organizações Sociais (OSs) e Organizações da Sociedade Civil de Interesse Público (OSCIPs) aos poucos vão deixando a militância reinvidicativa e passam a ter um perfil voltado à prestação de serviços, atuando junto ao Estado na execução destas políticas públicas.

A problemática desta condição é a distorção de postura que a sociedade civil acabou abarcando, ao assumir papéis que o Estado deveria ser protagonista. Neste sentido, Gohn (2004) diz que:

O empoderamento da comunidade, para que ela seja protagonista de sua própria história tem sido um termo que entrou para o jargão das políticas públicas e dos analistas, neste novo milênio (GOHN, 2004, p. 23).

o significado da categoria "empowerment" ou empoderamento como tem sido traduzida no Brasil, não tem caráter universal. Tanto poderá estar referindose ao processo de mobilizações e práticas destinadas a promover e impulsionar grupos e comunidades - no sentido de seu crescimento, autonomia, melhora gradual e progressiva de suas vidas (...); como poderá 
referir-se a ações destinadas a promover simplesmente a pura integração dos excluídos (...) (GOHN, 2004, 23).

Ainda de acordo com Gohn (2004), "uma sociedade democrática só é possível via o caminho da participação dos indivíduos e grupos sociais organizados".

Deste modo, a preocupação é que haja participação da sociedade civil na esfera pública, principalmente no que diz respeito à operacionalização das políticas públicas. Porém, como menciona a referida autora, "não é para substituir o Estado", mas sim reinvidicar e fiscalizar para que este cumpra o seu dever. Por isso, a participação ativa na esfera pública, que seja em plano local, contribuirá para o processo de transformação da sociedade.

De acordo com Nozabielli (2006),

A Assistência Social, na condição de política social, orienta-se pelos direitos de cidadania e não pela noção de ajuda ou favor. Questiona o clientelismo e a tutela presente nas práticas da assistência social por considerá-los um dos grandes desafios a ser superado, uma vez que não favorecem 0 protagonismo e a emancipação dos cidadãos usuários, e, consequentemente, a afirmação da lógica dos direitos sócio assistenciais (NOZABIELLI, 2006, p. 13).

Outro aspecto deturpador do real objeto das políticas públicas é que no Brasil, as políticas sociais costumam possuir a característica de resolver problemas emergentes, pois nem sempre são elaboradas se levando em consideração na resolução de problemas em longo prazo. Höfling (2001) aponta este fato ao mencionar que,

Políticas sociais se referem a ações que determinam o padrão de proteção social implementado pelo Estado, voltadas, em princípio, para a redistribuição dos benefícios sociais visando a diminuição das desigualdades estruturais produzidas pelo desenvolvimento socioeconômico (HÖFLING, 2001, p. 31).

Ou seja, as políticas públicas são planejadas de modo a se resolver um problema passado, e não evitar um problema futuro. Até mesmo as políticas de assistência social dentro do universo de políticas e programas institucionais, podem ser, portanto, averiguadas em relação a esta característica.

A formulação de Assistência Social conseguiu superar a tradição de benemerência e caridade, suportes do fisiologismo e de clientelismo, embora 
estas práticas ainda dominem. $O$ grande salto foi conceber a Assistência como direito de cidadania, política pública, prevendo ações de combate à pobreza e promoção do bem estar social, articulada às outras políticas, inclusive a econômica. Na prática, este compromisso entre o Estado e a sociedade para a criação de condições dignas de vida não vem se efetivando e a cultura da elite que tutela o carente ainda se mantém (TEIXEIRA, 2002, p. 9).

Deste modo, para que se consiga a real participação da sociedade civil na projeção destas políticas públicas é preciso que elas não sejam reduzidas a políticas estatais. Pelo contrário, elas precisam ser entendidas como de responsabilidade do Estado quanto à sua implementação e manutenção, mas devem ser elaboradas e executadas a partir de decisões que envolvem órgãos públicos e diversas organizações e agentes sociais relacionados à política pública que se quer implantar.

Para ilustrar este conceito, ao tratar dos desafios da economia solidária, EID (2007, p. 62) diz que,

Devem-se ter políticas públicas claras, estabelecidas em conjunto com os movimentos sociais e com a sociedade, fazendo parte de um planejamento estratégico onde esteja relacionado políticas sociais de entrega de dinheiro público durante certo período para pessoas necessitadas, enquanto um mecanismo para desafogar pressões da fome. No entanto, estas pessoas deverão estar comprometidas em conquistar a autonomia, enquanto que essa política deverá estar vinculada a uma política de formação de empreendimentos solidários e autogestionários (EID, 2007, p. 62).

Para estreitar um pouco o âmbito da análise a que este trabalho se propõe, foi escolhido um Programa governamental para fundamentar a discussão acerca da participação social em sua realização, tomando por base aspectos regionais de sua implementação. Assim, o objetivo deste trabalho é realizar uma breve discussão acerca do Programa Nacional de Alimentação Escolar - PNAE, apontando algumas potencialidades e fragilidades observadas na região do Pontal do Paranapanema (SP), no intuito de desmistificar a visão assistencialista projetada pela sociedade civil e sua participação na operacionalização.

Para tanto, foram observados alguns estudos de casos e legislações pertinentes, e analisado o Programa em si, de modo a comparar o que o mesmo propõe e o que os estudos realizados apontaram neste sentido. 


\section{POLÍTICAS PÚBLICAS DE ALIMENTAÇÃO ESCOLAR: BREVE CONTEXTO HISTÓRICO BRASILEIRO}

A década de 1930 é apontada por alguns teóricos como a época em que as primeiras políticas de enfrentamento da questão da fome e desnutrição foram elaboradas. Isto porque, surgia no meio acadêmico uma nova ciência, a Nutrologia ou Nutrição, como hoje é conhecida a ciência que estuda a composição dos alimentos e as necessidades humanas individuais destes alimentos.

Embora as ações estatais volvidas para o assunto da nutrição da população terem sido administradas desde o início do período colonial, efetivamente os primeiros passos direcionados a uma política social de alimentação e nutrição foram estabelecidos apenas entre os anos de 1937 e 1945, quando transformações econômicas, políticas e sociais ocasionadas e reforçadas com a Era Vargas, possibilitaram a descoberta científica da fome e, consequentemente, avigoraram a criação da prática profissional em nutrição. Neste período, ocorreu a instituição de uma política social de alimentação e nutrição.

Em 1940, é instituído o SAPS - Serviço de Alimentação da Previdência Social, fazendo com que o estado brasileiro administrasse uma política que se propusesse a solucionar o problema evidenciado pelos cientistas na época. Assim, segundo Barros e Tartaglia (2003), "a alimentação passa, então, da condição de apenas mais um campo de saber para a de uma política pública".

Avançando um pouco mais na História, a década de 1950 apresenta a implantação de programas de distribuição de alimentos a segmentos específicos da população. Em 1955, o governo brasileiro, por meio do Fundo Nacional de Desenvolvimento da Educação (FNDE), institui o PNAE - Programa Nacional de Alimentação Escolar, que garante, por meio da transferência de recursos financeiros, a alimentação escolar dos alunos de toda a educação básica matriculados em escolas públicas e filantrópicas. Segundo o Art. 4 da Lei oㅜ 11.947, de 16/06/2009, o PNAE objetiva: 
Contribuir para o crescimento e o desenvolvimento biopsicossocial, a aprendizagem, o rendimento escolar e a formação de hábitos alimentares saudáveis dos alunos, por meio de ações de educação alimentar e nutricional e da oferta de refeições que cubram as necessidades nutricionais durante 0 período letivo (BRASIL, Presidência da República, 2009, p.1).

Assim sendo, o PNAE dispõe-se a atender os imperativos nutricionais dos alunos durante o período escolar, colaborando para o desenvolvimento, a aprendizagem e o proveito escolar dos estudantes, contribuindo para a formação de hábitos alimentares saudáveis.

Conforme previsto no artigo 208, incisos IV e VII, da Constituição Federal o PNAE tem caráter suplementar, quando indica que:

o dever do Estado (ou seja, das três esferas governamentais: União, estados e municípios) com a educação é efetivado mediante a garantia de "atendimento em creche e pré-escola às crianças de zero a seis anos de idade" (inciso IV) e "atendimento ao educando no ensino fundamental, através de programas suplementares de material didático-escolar, transporte, alimentação e assistência à saúde" (inciso VII) (BRASIL, Senado Federal, 1988, p. 35).

O Fundo Nacional de Desenvolvimento da Educação é responsável pela assistência financeira, normatização, coordenação, acompanhamento, monitoramento e fiscalização da execução do programa, promovendo sua efetivação e eficácia. As entidades executoras são as Secretarias de Educação nas diversas esferas do poder, Prefeituras e Escolas Federais, além do Conselho de Alimentação Escolar - CAE.

De acordo com o disposto na Lei no 11.947, de 16/06/2009 (Art. 18), o CAE atua como colegiado deliberativo, instituído no âmbito dos estados, Distrito Federal e dos municípios, sendo o órgão responsável pelo recebimento e complementação dos recursos financeiros, e também pela execução do PNAE.O Conselho é formado por:

a) um representante indicado pelo Poder Executivo do respectivo ente federado;

b) dois representantes indicados pelos Conselhos Escolares, Associações de Pais e Mestres (ou entidades similares);

c) dois representantes das entidades de trabalhadores da educação e de discentes;

d) dois representantes indicados por entidades civis organizadas. 
Vale ressaltar que para a escolha dos representantes indicados nas letras b, c e d são necessárias realizações de assembleias específicas. Cada membro do CAE tem um suplente e mandato de quatro anos, podendo ser reconduzidos de acordo com indicações dos seus respectivos segmentos.

O Conselho de Alimentação Escolar - CAE faz cumprir dentro do Programa a participação da sociedade civil, prevista na Resolução/CD/FNDE № 38, de 16 de Julho de 2009, que dispõe sobre o atendimento da alimentação escolar aos alunos da educação básica no Programa Nacional de Alimentação Escolar - PNAE. Na região do Pontal do Paranapanema, objeto deste estudo, esta participação favorece a operacionalização do PNAE no sentido de aproximação da política pública à realidade local. Conforme aponta Gohn (2004, p. 24)“uma sociedade democrática só é possível via o caminho da participação dos indivíduos e grupos sociais organizados".

Quanto ao repasse, atualmente, o valor disponibilizado pela União a Estados e Municípios por dia letivo para cada aluno é definido de acordo com a etapa de ensino com base no censo escolar realizado no ano anterior ao do atendimento, de acordo com idade e série. O FNDE se baseia nos dados apresentados e efetiva o repasse do recurso financeiro. As Prefeituras Municipais, por sua vez, devem enviar a prestação de contas comprobatória até último dia do mês de fevereiro do ano subsequente. Para o ano de 2012, têm-se os seguintes valores por aluno:

Tabela 1: Demonstrativo do valor disponibilizado pela União a Estados e Municípios por dia letivo por aluno

\begin{tabular}{l|r} 
Nível escolar & Valor por aluno \\
\hline Creches & $\mathrm{R} \$ 1,00$ \\
\hline Pré-escola & $\mathrm{R} \$ 0,50$ \\
\hline Escolas indígenas e quilombolas & $\mathrm{R} \$ 0,60$ \\
\hline Ensino fundamental, médio e educação de jovens e adultos & $\mathrm{R} \$ 0,30$ \\
\hline Ensino integral (Mais Educação) & $\mathrm{R} \$ 0,90$ \\
Fonte: http://www.fnde.gov.br/index.php/programas-alimentacao-escolar. Organizado pela autora.
\end{tabular}


Portanto, tem-se que o orçamento do programa para 2012 é de $R \$ 3,3$ bilhões, para beneficiar 45 milhões de estudantes da educação básica e de jovens e adultos. Com a Lei ำ 11.947, de 16/6/2009, 30\% desse valor - ou seja, $R \$ 990$ milhões devem ser investidos na compra direta de produtos da agricultura familiar, medida que estimula o desenvolvimento econômico das comunidades. No ano de 2010, o programa atendeu (em nível nacional) 45,6 milhões de alunos, investindo $R$ \$ 3.034 milhões. No município de Presidente Prudente, o total de atendimentos no mesmo período foi de 37.871 alunos matriculados.

O programa é acompanhado e fiscalizado diretamente pela sociedade, por meio dos Conselhos de Alimentação Escolar (CAEs), pelo FNDE, pelo Tribunal de Contas da União (TCU), pela Secretaria Federal de Controle Interno (SFCl) e pelo Ministério Público.

De acordo com a Resolução/CD/FNDE № 38, de 16 de Julho de 2009, são princípios do Programa Nacional de Alimentação Escolar:

I - o direito humano à alimentação adequada, visando garantir a segurança alimentar e nutricional dos alunos;

II - a universalidade do atendimento da alimentação escolar gratuita, a qual consiste na atenção aos alunos matriculados na rede pública de educação básica;

III - a equidade, que compreende o direito constitucional à alimentação escolar, com vistas à garantia do acesso ao alimento de forma igualitária;

IV - a sustentabilidade e a continuidade, que visam ao acesso regular e permanente à alimentação saudável e adequada;

$\mathrm{V}$ - o respeito aos hábitos alimentares, considerados como tais, as práticas tradicionais que fazem parte da cultura e da preferência alimentar local saudáveis;

$\mathrm{VI}$ - o compartilhamento da responsabilidade pela oferta da alimentação escolar e das ações de educação alimentar e nutricional entre os entes federados, conforme disposto no art. 208 da Constituição Federal; e

VII - a participação da comunidade no controle social, no acompanhamento das ações realizadas pelos Estados, Distrito Federal e Municípios para garantir a execução do Programa (BRASIL, Ministério da Educação, 2009, p. 2).

A Resolução/CD/FNDE № 38, de 16 de Julho de 2009, também prevê no Capítulo VI, a aquisição de alimentos da agricultura familiar e do empreendedor familiar rural, sendo que do total dos recursos financeiros repassados para a merenda escolar, $30 \%$ devem ser gastos na aquisição de gêneros alimentícios destes 
produtores ou de organizações produtivas tradicionais (incluem-se as quilombolas e indígenas).

A operacionalização do PNAE na região do Pontal do Paranapanema, de características econômicas ruralistas, é realizada desde a década de 1990, quando o programa foi lançado nacionalmente. Porém, a forma de execução do programa na região é realizada de maneira mais flexível, pelo fato de os munícipios serem geograficamente menores, possibilitando um maior contato entre os atores responsáveis pela sua operacionalização. Este fato constitui-se em um facilitador para análise de suas características estruturais e de como alguns ajustes em busca de aperfeiçoamento e adequações à realidade regional podem contribuir para sua sustentação.

\section{ALGUMAS REFLEXÕES SOBRE A OPERACIONALIZAÇÃO DO PNAE NA REGIÃO DO PONTAL DO PARANAPANEMA}

Da maneira como foi concebido o Programa Nacional de Alimentação Escolar PNAE, e a forma como vem sendo operacionalizado, podem ser notadas algumas fragilidades e potencialidades em seu desempenho, as quais são tratadas a seguir.

Como fragilidades podem ser apontadas:

- Fragilidade na operacionalização no que diz respeito a conteúdos de educação alimentar a serem trabalhados nos temas transversais. Vale ressaltar que, de acordo com a Lei no 11.947/2009,

compete ao Ministério da Educação propor ações educativas que perpassem pelo currículo escolar, abordando o tema alimentação e nutrição e a inclusão da educação alimentar e nutricional no processo de ensino e aprendizagem dentro da perspectiva do desenvolvimento de práticas saudáveis de vida e da segurança alimentar e nutricional, conforme disposto Lei $n^{\circ} 11.947$, de 16 de junho de 20097/2009, em seu art. 15 (BRASIL, Presidência da República, 2009 , p. 3).

- A participação dos conselheiros deixa a desejar na execução de seu papel previsto na lei (fiscalização, acompanhamento, deliberações). 
- A estética da Lei № 11.947/2009é de difícil compreensão, principalmente para aqueles que não têm intimidade com o vocabulário político, visto que trata de três assuntos: 1. dispõe sobre o atendimento da alimentação escolar e do Programa Dinheiro Direto na Escola aos alunos da educação básica; 2. altera as Leis ํㅜ 10.880 , de 09/06/2004, 11.273, de 06/02/2006 e 11.507, de 20/07/2007; 3. revoga dispositivos da Medida Provisória oㅡ 2.178-36, de 24/08/2001 e a Lei oㅜ 8.913, de 12/07/1994. Neste item, acredita-se que ocorre certa confusão na leitura. Para maior clareza e entendimento do "leitor leigo", o texto da lei poderia ter sido organizado em capítulos, conforme os programas que a mesma regulamentou.

- A lei deveria ter previsto uma ação interinstitucional do Ministério da Educação e Mistério de Desenvolvimento Agrário determinando que a assistência técnica e extensão rural capacitassem os agricultores familiares na produção de alimentos ecologicamente corretos que compõem o cardápio da alimentação escolar.

- Não obstante o Programa ter sido iniciado em 2009, os agricultores, principalmente os pequenos produtores rurais e assentados, ainda não estão preparados para a participarem das chamadas públicas. A lei não previu uma capacitação junto aos agricultores familiares e suas associações/cooperativas, no sentido de qualificá-los a entender o processo e os procedimentos determinados pela lei no sentido de torna-los aptos às chamadas públicas.

- Os produtores rurais têm dificuldade em dispensar a produção, visto que há uma série de requisitos e critérios para participação na licitação, necessária para a participação no Programa. Sabe-se que, muitas vezes o pequeno produtor rural não dispõe de conhecimento necessário da parte administrativa e burocrática de tais questões. Porém, a Resolução/CD/FNDE № 38, de 16 de Julho de 2009 prevê esta participação, quando menciona que uma das diretrizes do PNAE é promover:

o apoio ao desenvolvimento sustentável, com incentivos para a aquisição de gêneros alimentícios diversificados, produzidos em âmbito local e preferencialmente pela agricultura familiar e pelos empreendedores familiares, priorizando as comunidades tradicionais indígenas e de remanescentes de quilombos(BRASIL, Ministério da Educação, 2009, p. 3). 
- O valor per capta previsto pelo Programa é ineficiente, em todas as modalidades apresentadas no quadro 1 (p. 6), em parte devido ao aumento no número de beneficiários, cuja projeção é calculada de acordo com o censo do ano anterior. Outro fator não considerado na base de cálculo é a alta inflacionária dos produtos alimentícios (em razão de mudanças climáticas, por exemplo) o que prejudica a diversidade de gêneros alimentícios. Além disso, conforme trata a Resolução/CD/FNDE № 38, de 16 de Julho de 2009, em seu Capítulo IV, Art. 9ํ, §3ํㅡㄴ o repasse do investimento pode ser parcelado:

A transferência de recursos realizada na forma deste artigo deverá ocorrer em até 10(dez) parcelas por ano, no prazo máximo de até 5 (cinco) dias úteis, a contar da efetivação do crédito realizado pelo FNDE(BRASIL. Ministério da Educação, 2009, p. 6).

- Os produtores rurais também apresentam dificuldade de acesso à informação das chamadas públicas sobre produtos, quantidades e valores que são disponibilizados pelo Programa em nível local, regional e nacional. A lei deveria determinar um portal na Internet único que atenda essa demanda, bem como elaborar publicações periódicas e disponibilizá-las em locais estratégicos, como escolas, bancos e órgãos de assistência técnica e extensão rural, como por exemplo a Coordenadoria de Assistência Técnica Integral - CATI/SP e a Fundação do Instituto de Terras do Estado de São Paulo - ITESP, entre outros.

Em contraponto às fragilidades, a seguir são apresentadas algumas potencialidades verificadas no Programa Nacional de Alimentação Escolar.

- O Programa apresenta preocupação em definir profissional especializado (Nutricionista) para gerenciar as atividades do Programa, conforme o disposto no Art.14 da Resolução/CD/FNDE № 38, de 16 de Julho de 2009:

Art. 14. A coordenação das ações de alimentação escolar, sob a responsabilidade dos Estados, do Distrito Federal e dos Municípios, será realizada por nutricionista habilitado, que deverá assumir a responsabilidade técnica do Programa, respeitando as diretrizes previstas na Lei $n^{\circ}$ $11.947 / 2009$ e nas legislações pertinentes, no que couber.

$\S 11^{\circ}$ Compete ao nutricionista responsável-técnico pelo Programa, e aos demais nutricionistas lotados no setor de alimentação escolar, coordenar o diagnóstico e o monitoramento do estado nutricional dos estudantes, planejar 
o cardápio da alimentação escolar de acordo com acultura alimentar, o perfil epidemiológico da população atendida e a vocação agrícola da região, acompanhando desde a aquisição dos gêneros alimentícios até a produção e distribuição da alimentação, bem como propor e realizar ações de educação alimentar e nutricional nas escolas (BRASIL. Ministério da Educação, 2009, p. 7).

- A inserção dos agricultores familiares nesse mercado institucional possibilita a comercialização de suas produções de forma direta com o consumidor, agregando valores e renda.

- O Programa busca envolver a sociedade civil, tanto na escolha dos alimentos, quanto no processo de fiscalização de repasses financeiros e produtos, conforme previsto na Resolução/CD/FNDE № 38, de 16 de Julho de 2009, que aponta:

\begin{abstract}
a importância da intersetorialidade por meio de políticas, programas, ações governamentais e não governamentais para a execução do Programa Nacional de Alimentação Escolar - PNAE, por meio de ações articuladas entre educação, saúde, agricultura, sociedade civil, ação social, entre outros (BRASIL. Ministério da Educação, 2009, p. 2).

o exercício do controle social, de caráter deliberativo, por meio da participação da comunidade, com a finalidade de garantir o acompanhamento e assessoramento da execução do PNAE(BRASIL. Ministério da Educação, 2009, p. 2).
\end{abstract}

Diante do exposto, o PNAE por vezes é recebido pela comunidade (tanto produtores quanto beneficiados), como uma política de cunho assistencialista, assim como muitas outras (Programa Bolsa Família, que incorpora os programas criados no Governo de Fernando Henrique Cardoso: Bolsa Escola, Cartão Alimentação, Auxilio Gás e Bolsa Alimentação).

O PNAE também é identificado como programa carente de objetivos educativos e de inclusão social, figurando-se apenas pela distribuição de alimentos. Porém, a Resolução/CD/FNDE № 38, de 16 de Julho de 2009, em seu Cap. V, Art. 13, aponta a educação alimentar como uma das ações de alimentação e nutrição na escola:

Art. 13. Para fins do Programa Nacional de Alimentação Escolar, será considerada educação alimentar e nutricional o conjunto de ações formativas que objetivam estimular a adoção voluntária de práticas e escolhas alimentares saudáveis, que colaborem para a aprendizagem, o estado de saúde do escolar e a qualidade de vida do indivíduo.

$\S 1^{\circ}$ São consideradas, entre outras, estratégias de educação alimentar e nutricional: a ofertada alimentação saudável na escola, a implantação e 
manutenção de hortas escolares pedagógicas, a inserção do tema alimentação saudável no currículo escolar, a realização de oficinas culinárias experimentais com os alunos, a formação da comunidade escolar, bem como o desenvolvimento de tecnologias sociais que a beneficiem (BRASIL. Ministério da Educação, 2009, p. 6).

$\mathrm{Na}$ região estudada, pode-se afirmar que a operacionalização do PNAE apresenta certa flexibilidade devido à facilidade de comunicação entre os atores envolvidos no processo. O profissional nutricionista geralmente apresenta sensibilidade na formatação do cardápio, observando a produção local, o tempo e a aptidão dos produtores rurais, que por sua vez, dependem de condições climáticas e recursos financeiros para diversificar a produção. Somando-se a isso, o técnico agrônomo também precisa estar preparado para capacitar o agricultor, principalmente no planejamento anual da produção, de forma que este tenha sempre algo a oferecer à merenda escolar, de preferência produtos ecologicamente corretos. Outro fator apontado como relevante é o relacionamento entre o nutricionista e o funcionário responsável pela licitação. Se estes dois profissionais trabalharem de maneira integrada, facilitará a elaboração do edital das chamadas públicas, constando corretamente a qualidade, quantidade e período de entrega do produto durante todo o ano letivo.

Considerando-se a concepção de política pública instituída e as disposições apresentadas nos documentos que legitimam o Programa Nacional de Alimentação Escolar - PNAE, se pode deduzir que na região estudada, a autonomia dos municípios em colocar o "Estado em ação" de acordo com as necessidades locais constitui-se em fator crucial para o desenrolar do mesmo de maneira sustentável a todos os envolvidos e beneficiários. Neste sentido afirma Neves (2007, p. 261) que:

As normas são fundamentadas ao exercício de políticas qualificadas como públicas, embora elas devam encontrar as condições para se fazerem cumprir. As políticas públicas não podem se limitar a um de seus aspectos: o normativo. As normas são a condição para sua implementação, por conseguinte não podem desconhecer os meandros inerentes à sua incorporação, nem sempre pacífica e sob adesão plena.

Assim considerada a política pública, ela pode se aproximar mais da realidade dos beneficiários, deixando de apresentar a característica de apaziguadora de 
conflitos imediatos, fator recorrente na prática. A participação da comunidade na operacionalização do programa por meio dos Conselhos de Alimentação Escolar (CAEs) favorece o sentimento de pertença (pertencimento) no processo de construção de algo para o bem comum, essencial à consciência coletiva, isto é, o empoderamento do indivíduo em prol do coletivo, num relacionamento de respeito e compromisso social.

Outro fator relevante a ser mencionado é que o aspecto assistencialista das políticas públicas e programas propostos pelo governo ainda se mostra um fato, principalmente quando se leva em conta os aspectos sociais e econômicos do país, de caráter desigual. Este fator se reflete na implantação do PNAE na região estudada, principalmente quando se observa que a nutrição escolar, em seu âmbito político, não ocupa posição de destaque na preocupação dos educadores.

\section{CONCLUSÃO}

A partir das leituras e análise do Programa Nacional de Alimentação Escolar PNAE e das legislações pertinentes, constatou-se que sua disposição contribui para a melhoria da alimentação escolar e, consequentemente, da saúde dos beneficiários, ao proporcionar a formação de hábitos alimentares saudáveis. Também favorece a produção e promove segurança econômica aos agricultores envolvidos com o cultivo dos alimentos.

Porém, ao verificar sua aplicabilidade, por meio dos estudos de caso levantados, o trabalho revelou que, quanto à produção de alimentos, na verdade, são os grandes atacadistas os vencedores das licitações. Estes produtores atrasam a entrega dos produtos, em parte devido à falta de planejamento ou imprevistos climáticos, e dificuldade de transporte devido às más condições das estradas rurais. Este fator acaba por descompassar o calendário do Programa com o das escolas. 0 programa também deixa a desejar quanto à participação da sociedade civil, pois apesar de prever um Conselho de Alimentação Escolar, o mesmo deve se submeter à realidade, principalmente econômica, dentro do processo. 
Deste modo, pode-se inferir que uma maior participação da sociedade, representada pelos diversos segmentos sociais, empenhada em pressionar o Estado, poderia contribuir para a desmistificação do objeto norteador do programa, que se distancia do assistencialismo. Esta participação social também pode contribuir para o empoderamento das comunidades envolvidas, principalmente as produtoras dos gêneros alimentícios, quando estas fazem parte desse mercado institucional.

\section{REFERÊNCIAS}

BARROS, M. S. C.; TARTAGLIA, J. C. A política de alimentação e nutrição no Brasil: breve histórico, avaliação e perspectivas. Alimentos e Nutrição Araraquara, Vol. 14, No 1 (2003). Disponível em http://serv-bib.fcfar.unesp.br/seer/index.php/alimentos/article/view/847. Acesso em 02/10/2012.

BRASIL. Constituição (1988). Constituição da República Federativa do Brasil.

Brasília: Senado Federal, 1988.

BRASIL. Ministério da Educação. Desenvolvida pelo Fundo Nacional de Desenvolvimento da Educação. Apresenta Alimentação Escolar. Disponível em http://www.fnde.gov.br/index.php/programas-alimentacao-escolar. Acesso em 31/10/2012.

BRASIL. Ministério da Educação. Fundo Nacional de Desenvolvimento da Educação. Conselho Deliberativo. Resolução/CD/FNDE № 38, de 16 de Julho de 2009. Dispõe sobre o atendimento da alimentação escolar aos alunos da educação básica no Programa Nacional de Alimentação Escolar PNAE.

BRASIL. Presidência da República. Casa Civil. Subchefia para Assuntos Jurídicos. Lei no 11.947, de 16 de junho de 2009. Dispõe sobre o atendimento da alimentação escolar e do Programa Dinheiro Direto na Escola aos alunos da educação básica; altera as Leis nos 10.880, de 9 de junho de 2004, 11.273, de 6 de fevereiro de 2006, 11.507, de 20 de julho de 2007; revoga dispositivos da Medida Provisória no 2.178-36, de 24 de agosto de 2001, e a Lei no 8.913, de 12 de julho de 1994; e dá outras providências.

COSTA, Liliam Magda Campos. O Programa Nacional de Alimentação Escolar (PNAE) na perspectiva dos usuários: um estudo de caso. Dissertação de Mestrado. Fortaleza, 2004. Disponível em: http://www.prodema.ufc.br/dissertacoes/091.pdf. Acesso em 01/10/2012.

EID, F. Descentralização do Estado, economia solidária e políticas públicas. Revista ORG \& DEMO (Marília), v. 8, n.1/2, Jan.-Jun./Jul.-Dez., p. 47-66, 2007.

GOHN, Maria da Glória. Empoderamento e participação da comunidade em políticas sociais. Saúde e Sociedade v.13, n.2, p.20-31, maio-ago 2004. Disponível em: http://www.scielo.br/scielo.php?script=sci_arttext\&pid=S0104-12902004000200003\&lng=en\&nrm=iso. Acesso em 04/11/2012.

NEVES, Delma Pessanha. Agricultura familiar: quantos ancoradouros? In: FERNANDES, Bernardo Mançano; MARQUES, Marta Inez Medeiros, SUZUKI, Julio Cesar. Geografia Agrária: teoria e poder. Col. Geografia em Movimento. São Paulo: Expressão Popular, 2009, p. 211- 270. 
NOZABIELLI, Sônia Regina. O processo de afirmação da assistência social como política social. Serviço social em revista. v. 8, no 2, jan/jun. Departamento de Serviço Social da Universidade Estadual de Londrina, 2006. http://www.uel.br/revistas/ssrevista/c-v8n2_sonia.htm. Acesso em $10 / 11 / 2012$

SECCHI, Leonardo. Políticas Públicas: conceitos, esquemas de análise, casos práticos. São Paulo: Cengage Learning, 2012.

TEIXEIRA, Elenaldo Celso. Políticas Públicas - O papel das políticas públicas no desenvolvimento local e na transformação da realidade. Associação de Advogados/as de Trabalhadores/as Rurais AATR/Bahia. 2002. Disponível em: http://www.escoladebicicleta.com.br/politicaspublicas.pdf. Acesso em: 12/11/2012.

VASCONCELOS, F.A.G. Combate à fome no Brasil: uma análise de Vargas a Lula. Revista de Nutrição, v.18, n. 4, jul./ago. Campinas, 2005, p.439-457. 